Assessment of ramis, condyl e, masset er miscle, and occl usal force bef ore and after sagi ttal spl it ramis ost eot ony in pat i ent s wi th mandi bul ar prognat hi sm

\begin{tabular}{|l|l|}
\hline 著者 & $\begin{array}{l}\text { Ueki Koi chi ro, Okabe Kat suhi ko, Mikozawa Aya, } \\
\text { M yazaki Nao, Mar ukawa Kohei, Hashi ba Yukar i, } \\
\text { Nakagawa K yonasa, Yanantot o Et suhi de }\end{array}$ \\
\hline $\begin{array}{l}\text { j our nal or } \\
\text { publ i cat i on ti tl e }\end{array}$ & $\begin{array}{l}\text { Or al Sur gery, Or al Medi ci ne, Or al Pat hol ogy, } \\
\text { Or al Radi ol ogy and Endodont ol ogy }\end{array}$ \\
\hline vol une & 108 \\
\hline number & 5 \\
\hline page r ange & $679-686$ \\
\hline year & $2009-11-01$ \\
\hline URL & ht t p: //hdl . handl e. net /2297/19134 \\
\hline
\end{tabular}


Assessment of ramus, condyle, masseter muscle, and occlusal force before and after sagittal split ramus osteotomy in patients with mandibular prognathism

KOICHIRO UEKI, DDS, PhD\#; KATSUHIKO OKABE, DDS*; AYA MUKOZAWA, DDS*; MAO MIYAZAKI, DDS*; KOHEI MARUKAWA, DDS, PhD $\dagger$; YUKARI HASHIBA, DDS, PhD $\dagger$; KIYOMASA NAKAGAWA, DDS, PhD $\ddagger$; ETSUHIDE YAMAMOTO, DDS, PhD $\S$.

\# Assistant Professor.

* Graduate Student.

$\dagger$ Clinical Fellow.

† Associate Professor.

$\S$ Chief Professor.

Department of Oral and Maxillofacial Surgery, Graduate School of Medicine, Kanazawa University, 13-1 Takaramachi, Kanazawa 920-8641, Japan.

Address correspondence to: Koichiro Ueki, DDS, PhD,

Department of Oral and Maxillofacial Surgery, Graduate School of Medicine, Kanazawa University, 13-1 Takaramachi, Kanazawa 920-8641, Japan.

Tel: +81-76-265-2444; Fax: +81-76-234-4268

E-mail: kueki@med.kanazawa-u.ac.jp 
Assessment of ramus, condyle, masseter muscle, and occlusal force before and after sagittal split ramus osteotomy in patients with mandibular prognathism 


\title{
Assessment of ramus, condyle, masseter muscle, and occlusal force before and after sagittal split ramus osteotomy in patients with mandibular prognathism
}

\begin{abstract}
Purpose: The purpose of this study was to examine the relationship between the morphologies of the masseter muscle and the ramus and occlusal force before and after sagittal split ramus osteotomy (SSRO) in patients with mandibular prognathism.

Patients and Methods: The study group consisted of 26 patients with mandibular prognathism. All patients underwent bilateral SSRO as well as three-dimensional computed tomography and masseter muscle, ramus and condyle were measured preoperatively and at 1 year postoperation. Occlusal force and contact area were also recorded with pressure-sensitive sheets.

Results: In the cross-sectional area of the masseter muscle, there were no significant differences between the pre and postoperative statuses. However, postoperative ramus width and area were significantly larger than preoperative values $(\mathrm{P}<0.0001)$. Postoperative right condylar area was significantly larger than the preoperative value $(\mathrm{P}=0.0120)$. Occlusal force and contact area 1 year after surgery were significantly larger than the preoperative values $(\mathrm{P}=0.0016, \mathrm{P}=0.0190)$.

Conclusion: This study suggested that the masseter muscle area did not significantly differ from preoperative status 1 year after SSRO, although occlusal force, contact area and ramus area and width increased significantly 1 year after SSRO.
\end{abstract}

Key word: Computed tomography

Masseter muscle

Occlusal force

Sagittal split ramus osteotomy 


\section{Introduction}

Sagittal split ramus osteotomy (SSRO) is the most frequently used procedure for mandibular prognathism. Orthognathic surgery can alter not only morphological aspects, but also functional aspects. Previous studies suggested that occlusal force 1year after SSRO was larger than preoperative force with a pressure-sensitive system. ${ }^{1-4}$

On the other hand, muscle cross-sectional size and muscle lever mechanics are important determinants of the magnitude of bite force. The cross-sectional size of a muscle bears a direct relationship to maximum tension-generating capacity, ${ }^{5}$ and the length of its lever arm relative to the mandibular condyle determines the maximum torque that the muscle can exert. ${ }^{6}$ Previous studies suggested that the cross-sectional area and thickness of masticatory muscles, as parameters of the functional ability of those muscles, are significantly correlated with biting force and the properties of facial morphology. ${ }^{72}$ Various methods have been described for measuring muscle morphology. ${ }^{13,14}$ The direction and cross-sectional area of the masseter muscle have frequently been measured from cross-sectional images obtained by computed tomography (CT) and magnetic resonance imaging (MRI). ${ }^{15-17}$

It has been suggested that condylar morphology is also associated with occlusal force, on the basis of biomechanical analysis. ${ }^{18}$ However, there are few reports relating condylar morphology and occlusal force with CT in patients with mandibular prognathism.

CT evaluation of the masseter muscle in mandibular prognathism has shown that the morphology of the masseter muscle in patients with mandibular prognathism is significantly different from that in normal subjects. ${ }^{19}$ Furthermore, a significant reduction in the cross-sectional area of the masseter muscle was seen, and a tendency to revert back to the normal dimension was seen between 6 months and year postoperation. ${ }^{20}$ However, there were also few reports regarding the relation between masseter muscle, ramus and occlusal force with CT in patients with mandibular prognathism.

The purpose of this study was to examine the relationship between the morphologies of the masseter muscle and the ramus including condyle and the occlusal force in patients with 
mandibular prognathism.

\section{Patients and Methods}

The study group consisted of 26 women patients (mean age of 25.5 years, ranging 16-42 years). Informed consent was obtained from patients and the study was approved by Kanazawa University Hospital.

22 of 26 patients were diagnosed as mandibular prognathism and the remaining 4 patients were diagnosed as mandibular prognathism with maxillary retrognathia. However, none had severe TMJ symptoms.

\section{Surgery}

Of the 26 patients in this study, 22 underwent bilateral SSRO. The other 4 patients underwent SSRO and a Le Fort I osteotomy; rigid fixation was achieved with min-plates and monocortical screws. The plates were bent to prevent the proximal segments from rotating internally. Therefore the gap was created between the osteotomy surfaces on both sides (Fig.1). ${ }^{21}$ Mean setback amount was right $6.2 \pm 3.0 \mathrm{~mm}$ and left $6.6 \pm 3.2 \mathrm{~mm}$. Immediately after surgery, elastic was placed to maintain the ideal occlusion without intemaxillary fixation. The patients did not receive any physical therapy after surgery. All patients received orthodontic treatment before and after surgery.

\section{Measurements with three-dimensional computed tomography}

Tomographs of the mandible were obtained while in the resting position using a high-speed advantage-type computed tomography (CT) generator (GE Medical Systems, Milwaukee, WI, USA)(CT high-speed advantage is a high resolution whole body computed tomography scanner capable of routine 1.0 second scans with 3.0 second reconstruction), with each sequence taken $1.5 \mathrm{~mm}$ apart in the horizontal plane parallel to the Frankfurt horizontal (FH) plane (120 kV, average $170 \mathrm{~mA}$, scanning time $40 \mathrm{sec}$ ). The resulting 
images were stored in the attached workstation computer and three-dimensional (3-D) reconstruction was performed. A lateral view of the 3-D image was reconstructed by superimposition. ExaVision LITE version 1.10 medical imaging software (Ziosoft, Inc, Tokyo, Japan) and Med View version 5.0 (LEXI Co, Tokyo, Japan) were used for 3D morphologic measurements (Figs. 2-4).

The RL line was determined as the line between the most anterior points of the bilateral auricles at the plane parallel to the FH plane. Multi planner reconstruction can be established in the software, so that the arbitrary plane can be moved parallel to the plane that the RL line was determined. The horizontal plane $5 \mathrm{~mm}$ above the mandibular foramen parallel to the FH plane was identified in right and left side, and masseter muscle, ramus and condyle were measured in each side pre- and 1 year postoperatively.

1) Ramus length: The distance between the most anterior point and most posterior point of the ramus

2) Ramus width: The thickest distance of the ramus parallel to the RL line

3) Ramus area: Square of ramus

4) Masseter length: The distance between the most anterior point and most posterior point of the masseter muscle

5) Masseter width: The thickest distance of the masseter muscle parallel to the RL line

6) Masseter area: Square of masseter muscle

1)-6) were measured in same plane, in each side.

7) Condylar length: The distance between the most medial point and most lateral point of the ramus on the plane parallel to $\mathrm{FH}$ where maximum area of condyle was recognized

8) Condylar width: the thickest distance perpendicular to the condylar length on the parallel plane to FH where maximum area of condyle was recognized

9) Condylar area: Area of condyle on the plane parallel to FH where maximum area of condyle was recognized

10) Masseter vertical length: 3 dimensional distance between gonion point and the most 
inferior point on the temporo-zygomatic suture

11) Masseter direction angle: The angle between the masseter vertical length and the FH plane

All CT images were measured by an author (K.U.). Fifteen patients were selected calculated using Dahlberg's formula ${ }^{22}$ :

$$
\mathrm{ME}=\sqrt{\sum d^{2} / 2 n}
$$

where $d$ is the difference between 2 registrations of a pair, and $n$ is the number of double registrations. The random errors did not exceed $0.21 \mathrm{~mm}$ for the linear measurements, 2.0 $\mathrm{mm}^{2}$ for the square measurements and $1.52^{\circ}$ for angular variables,.

\section{Occlusal force measurement}

Occlusal force and contact area were measured with a pressure-sensitive system before and one year after surgery. This system consists of a pressure-sensitive sheet (Dental Prescale; Fuji Photo Film Co., Tokyo, Japan) and its analyzing apparatus (Dental Occlusion Pressuregraph FPD-705; Fuji Photo Film Co.) connected to a personal computer. Each patient was seated with his or her head in an unsupported natural position, looking forward. The pressure-sensitive sheet was placed between the maxillary and mandibular teeth and the patient was instructed to bite as forcefully as possible for about 3 seconds. The sheet was read and analyzed by the Dental Occlusion Pressure graph and the results were put into the computer and visualized on the display screen.

\section{Statistical analysis}

Data of masseter muscle, ramus, condyle and bite force were statistically analyzed with StatView $^{\text {TM }}$ version 4.5 software (ABACUS Concepts, Inc., Berkeley, CA, USA). The statistical significance of a difference between pre- and postoperative values was analyzed by paired t-test. The relationships among the bite force, the area of masseter muscle, the area of ramus, and condylar area were evaluated using simple linear regression analysis. 


\section{Results}

Pre and postoperative cross-sectional area of the masseter muscle did not differ significantly. However, postoperative ramus width and area were significantly larger than the preoperative values on both sides $(\mathrm{P}<0.0001)$. Postoperative right condylar area was significantly larger than preoperative value $(\mathrm{P}=0.0120)$. Significant decreases were found in left masseter vertical length $(\mathrm{P}=0.0029)$ and left masseter angle $(\mathrm{P}=0.0375)$ postoperation.

Occlusal force 1 year after surgery was significantly larger than the preoperative value $(\mathrm{P}=0.0016)$. A significant increase was also found in contact area $(\mathrm{P}=0.0240)$.

When statistic analysis was performed using the total values (right +left), postoperative ramus width, ramus area and condylar area were significantly larger than the preoperative values $(\mathrm{P}<0.0001, \mathrm{P}<0.0001, \mathrm{P}=0.0392)$.

With regard to the difference between right and left, there were significant differences in ramus length $(\mathrm{P}=0.0231)$, ramus width $(\mathrm{P}=0.0188)$, masseter length $(\mathrm{P}=0.0366)$ and maseter width $(\mathrm{P}<0.0001)$ preoperation, ramus length $(\mathrm{P}=0.0106)$, masseter length $(\mathrm{P}=0.0269)$, masseter width $(\mathrm{P}=0.0207)$ and condylar area $(\mathrm{P}=0.0190)$ postoperation. However, there were no significant differences in ramus area and masseter area (Table.1).

Preoperative occlusal force and contact area showed significantly negative correlations to total condylar width (adjusted $\mathrm{R}^{2}=0.230, \mathrm{P}=0.0077$ )(Fig. $5 \mathrm{~A}$ ), however there was no significant difference after surgery.

There were significant positive correlations between occlusal force and total masseter width (adjusted $\mathrm{R}^{2}=0.120, \mathrm{P}=0.0462$ )(Fig. 5B), between contact area and total masseter width (adjusted $\mathrm{R}^{2}=0.202$, $\mathrm{P}=0.0212$ )(Fig. 5C) preoperation, however there were no differences after surgery.

There were positive significant correlations between total ramus area and total masseter area, before- (adjusted $\mathrm{R}^{2}=0.196, \mathrm{P}=0.0135$ ) (Fig. 6A) and after surgery (adjusted $\mathrm{R}^{2}$ $=0.383, \mathrm{P}=0.0004)$ (Fig. 6B). 


\section{Discussion}

The relationship between masticatory muscle and occlusal force before and after orthognathic surgery is very important. Several studies have used the pressure-sensitive sheet to report results after SSRO. ${ }^{1-4}$ Hattori et al. evaluated the reliability of this device for occlusal force measurement, both on a subject and on casts. ${ }^{23}$ They reported the linear relationship between applied and measured loads. They calculated occlusal force during maximum voluntary clenching of the subject ranged from 8 to $60 \mathrm{~N}$ at the premolars and 63 to $330 \mathrm{~N}$ at the molars. ${ }^{23}$ Harada et al. reported that both bite force and occlusal contact area were the lowest 2 weeks after surgery and recovered to the preoperative level between 8 weeks and 3 months, then they increased and exceeded the preoperative level at 6 months after surgery. ${ }^{1}$ Nagai et al. reported that the occlusal contact area and bite force of patients 1 month after the operation had decreased to below preoperative value, these values 12 months after the operation had increased by 2.0 and 1.8 times in women compared with the preoperative values. ${ }^{2}$ In our previous study, bite force and occlusal contact area were the lowest at 1 month after surgery. However, they increased to the preoperative levels between 3 and 6 months after surgery. ${ }^{4}$ Ohkura et al. have reported that mean bite force in women prognathism patients was $189.8 \mathrm{~N}$ preoperation, 345.1 N after 1 year, and $401.4 \mathrm{~N}$ after 2 years. ${ }^{3}$ In our previous study, mean bite force in women prognathism patients was $305.8 \mathrm{~N}$ preoperation and $405.2 \mathrm{~N}$ after 1 year. ${ }^{4}$ In this study, mean bite force in women prognathism patients was 429.9.1 N preoperation and 513.3 N after 1 year. Postoperative occlusal force was significantly larger than the preoperative one. Occlusal contacts showed a similar tendency.

Proffit et al. have stated that bite force is primarily affected by two factors: the amount of force generated by the masticatory muscles and the length of their moment arms. ${ }^{24}$ Throckmorton et al. proposed that the surgically altered geometry might influence the

maximum bite force directly by altering the mechanical advantage of individual muscles. ${ }^{25}$ They noted that mandibular setback surgery generally increased the mechanical advantage, whereas advancement surgery decreased it. However, they found in another investigation 
that the bite forces in the mandibular setback group were smaller than those in the mandibular advancement group postoperation. As one explanation for this finding, the authors suggested that the surgically induced changes in mechanical advantage were so small that they failed to affect the bite force. ${ }^{26}$

Computer tomography (CT) has made it possible to measure the cross-sectional areas of the upper arm muscles and the jaw muscles in living subjects. ${ }^{15,27}$ Furthermore, the cross-sectional area has been used frequently as a parameter of muscle size because it is highly correlated with muscle volume. ${ }^{13,14}$

$\mathrm{Xu}$ et al. reported that in Japanese subjects, masseter muscle area was $570 \mathrm{~mm}^{2}$ in males and $487 \mathrm{~mm}^{2}$ in females. ${ }^{17}$ However, Ando stated that in Japanese subjects, masseter muscle area was 381 to $399 \mathrm{~mm}^{2}$ in males and 288 to $293 \mathrm{~mm}^{2}$ in females. ${ }^{28}$ Ariji has reported that the cross-sectional area of the masseter muscle in female patients with mandibular prognathism was an average of $284.1 \mathrm{~mm}^{2}$, which is significantly smaller than that in normal subjects (an average of $322.4 \mathrm{~mm}^{2}$ ). ${ }^{19}$ These were measured on the original axial image at a level approximately $1 \mathrm{~cm}$ above the occlusal plane and calculated according to a formulae. ${ }^{19}$ In our previous study, the area was $365.2 \mathrm{~mm}^{2}$ on the right side and $372.2 \mathrm{~mm}^{2}$ on the left side in cases of prognathism with symmetry, and $365.0 \mathrm{~mm}^{2}$ on the deviation side and $363.2 \mathrm{~mm}^{2}$ on the non-deviation side in cases of prognathism with asymmetry. ${ }^{29}$ These values were larger than previously reported values by Ariji et al. ${ }^{19}$, because the horizontal plane $5 \mathrm{~mm}$ above the mandibular foramen parallel to the $\mathrm{FH}$ plane were used in our previous study. In the previous study, no significant difference in the area of the masseter muscle was found between the symmetry and asymmetry groups. ${ }^{29}$ Furthermore, no statistically significant difference in the area of the masseter muscle was found between the deviation side and the non-deviation side. In this study, there was no significant difference in the masseter area pre- and postoperation, similar to the previous study. However, there were significant differences between right and left in ramus length, ramus width, masseter length and masseter width preoperation, ramus length, masseter length, masseter width and condylar area postoperation, although the reason was still unclear. Although, in this study the difference between right and left could not be identified 
on the basis of frontal cephalometric analysis, we could not help understanding that the difference between right and left existed in some measurements.

In the study measuring the cross sectional area of masseter muscle with CT for mandibular prognathism patients after SSRO, Katsumata et al. found that a significant reduction was seen 3 months postoperation and a tendency to revert back between 6 months and 1 year postoperation, however, masseter muscle length was unchanged. ${ }^{20}$ They concluded that temporary atrophy was observed immediately after SSRO, but recovered within one year after SSRO. ${ }^{20}$ In this study, CT was not performed after 3 and 6 months, therefore the decrease in the masseter muscle area could not be seen. However, masseter muscle area after 1 year did not differ from that obtained preoperative, which is similar to the previous report. ${ }^{20}$ Furthermore, the postoperative masseter vertical length tended to be shorter than the preoperative value, in this study. The gonion point moved posterior-superiorly and was accompanied with setback of the distal segment.

The variation in jaw-muscle strength is associated with a vertical craniofacial morphology. ${ }^{7}$ Measurements of bite force and electromyographic activity indicate that long -faced (dolichofacial) individuals have weak jaw muscles as compared with normal and short-faced individuals (brachyfacial). ${ }^{8-12}$ It was clear that condylar morphology also reflected the dynamic relationship strongly ${ }^{18}$, although it was not obvious that occlusal force was related to the cross sectional area of condylar area. A previous study suggested that differences in skeletal patterns induced differences in stress distribution on the TMJ; the morphology of the TMJ was also associated with stress direction and distribution on the condyle. $^{18}$ In another study, there were no significant differences between pre- and postoperative horizontal changes in the condylar long axis or in the antero-posterior and medio-lateral displacement of the condylar head, after SSRO. ${ }^{29}$ Katsumata found that IVRO subjects had a higher incidence of remodeling than the SSRO group. ${ }^{30}$ Zhao et al. reported that minimal alteration in articular cartilage was found in the SSRO group. ${ }^{31}$ These studies suggested that condylar displacement and bony remodeling were very small after SSRO. ${ }^{29}$ In this study, preoperative occlusal force showed significant negative correlations to the condylar width. Significant postoperative increase of condylar area was shown. 
When the proximal segment is fixed by plate or screw, slight position and angle change occurs. The plane position measured the condylar area might change relatively or actual remodeling of condyle might occur in companied with the condylar displacement.

Our previous report suggested that bite force was significantly positively correlated to masseter muscle area and masseter area was correlated to ramus area in preoperative the state. ${ }^{15}$ However, the postoperative cross sectional shape of ramus was obviously different from preoperative one but, the cross sectional area of ramus was significantly larger than the preoperative value. This postoperative increase in ramus might partially depend on our surgical method reported previously. ${ }^{21}$ In this method, the gap between the proximal and distal segment is created by a bent plate, preventing formation of a large bony contact. Therefore, the space between distal and proximal segment filled with new bone, and the ramus width can increase. In this study, 1 year after SSRO, masseter muscle area did not change, but occlusal force increased. Furthermore, there were positive significant correlations between occlusal force and masseter width, between contact area and masseter width preoperation, however there were no differences 1year postoperation. Regarding the correlations between bite force and morphology such as masseter muscle, ramus and condyle, many of the preoperative correlations were weak. A number of the measurements had higher varience after surgery than before, possible contributing to the lack of significant correlations after surgery. However, we could not identify what factors had caused relatively low maximum bite force. Investigation using other physical examination such as electromyography (EMG) might be helpful. The study by Ohkura et al. suggested that occlusal force 3 years after SSRO reached the highest recorded value at the end of follow-up (after 3 years). ${ }^{3}$ Perhaps the masseter muscle area was not stable and had not completely adapted to the new occlusion and skeletal morphology after 1 year, however it might increase at 2-3 years after surgery. Therefore, further investigation for long follow up will be necessary. 


\section{References}

1) Harada K, Watanabe M, Okura K, Enomoto S: Measure of bite force and occlusal contact area before and after bilateral sagittal split ramus osteotomy of the mandible using a new pressure-sensitive device: A preliminary report. J Oral Maxillofac Surg 2000; 58: 370-373.

2) Nagai I, Tanaka N, Noguchi M, Suda Y, Sonoda T, Kohama G: Change in occlusal state of patients with mandibular prognathism after orthognathic surgery: a pilot study. $\mathrm{Br} \mathrm{J}$ Oral Maxillofac Surg 2001; 39: 429-433.

3) Ohkura, Harada K, Morishima S, Enomoto S: Changes in bite force and occlusal contact area after orthognathic surgery for correction of mandibular prognathism. Oral Surg Oral Med Oral Pathol Oral Radiol Endod 91: 141-145, 2001.

4) Ueki K, Marukawa K, Shimada M, Nakagawa K, Yamamoto E: Changes in occlusal force after mandibular ramus osteotomy with and without Le Fort I osteotomy. Int J Oral Maxillofac Surg 2007; 36: 301-304.

5) Weijs WA, Hillen B: Cross-sectional areas and estimated intrinsic strength of the human jaw muscles. Acta Morphol Neel-Scand 1985; 23: 267-274.

6) Pruim GJ, DE, Jongh HJ, Ten Bosch JJ: Force acting on the mandible during bilateral static bites at different bite force levels. J Biomech 1980; 13: 755-763.

7) Throckmorton GS, Ellis E $3^{\text {rd }}$, Buschang PH: Morphological and biomechanical correlates with maximum bite forces in orthognathic surgery patients. J Oral Maxillofac Surg 2000; 58: 515-24

8) Sassouni V: A classification of skeletal facial types. Am J Orthod 1969; 55: 109-123.

9) Ringqvist $M$ : Isometric bite force and its relation to dimensions of facial skeleton. Acta Odontol Scand 1973; 31: 35-42.

10) Ingervall B: Facial morphology and activity of temporal and lip muscles during swallowing and chewing. Angle Orthod 1976; 46: 372-380.

11) Proffit W, Fields HW, Nixon WL: Occlusal force in normal- and long-face adults. J Dent Res 1983; 62: 566-571.

12) Ingervall $B$, Bitsanis $E$ : A pilot study of the effect of masticatory muscle training on 
facial growth in long-face children. Eur J Orthod 1987; 9: 15-23.

13) van Spronsen PH, Weijs WA, Valk J, Prahl-Andersen B, van Ginkel FC: Comparison of jaw -muscle bite-force cross-sections obtained by means of magnetic resonance imaging and high-solution CT scanning. J Dent Res 1989; 68: 1765-1770.

14) Bakke M, Tuxen A, Vilmann P, Jensen BR, Vilmann A, Toft M: Ultrasound image of human masseter muscle related to bite force electromyography, facial morphology, and occlusal factors. Scand J Dent Res 1992; 100: 164-171.

15) Weijs WA, Hillen B: Relationships between the physiological cross-section of the human jaw muscles and their cross-sectional area in computer tomograms. Acta Anat 1984; 118: 129-138.

16) van Spronsen PH, Weijs WA, Valk J, Prahl-Andersen B, van Ginkel FC: Relationships between jaw muscle cross-sections and craniofacial morphology in normal adults, studied with magnetic resonance imaging. Eur J Orthod 1991; 13: 351-361.

17) Xu JA, Yuasa K, Yoshimura K, Kanda S: Quantitative analysis of masticatory muscles using computed tomography. Dentomaxillofac Radiol 1994; 23: 154-158.

18) Ueki K, Nakagawa K, Takatsuka S, Yamamoto E, Laskin DM: Comparison of the stress direction on the TMJ in patients with class I, II and III skeletal relationship. Orthod Craniofac Res 2008; 11: 43-50.

19) Ariji Y, Kawamata A, Yoshida K, Sakuma S, Nawa H, Fujishita M, Ariji E: Three-dimensional morphology of the masseter muscle in patients with mandibular prognathism. Dentomaxillofac Radiol 2000; 29: 113-118.

20) Katsumata A, Fujishita M, Ariji Y, Ariji E, Langlais RP: 3D CT evaluation of masseter muscle morphology after setback osteotomy for mandibular prognathism. Oral Surg Oral Med Oral Pathol Oral Radiol Endod 2004; 98: 461-470.

21) Ueki K, Degerliyurt K, Hashiba Y, Marukawa K, Nakagawa K, Yamamoto E: Horizontal changes in the condylar head after sagittal split ramus osteotomy with bent plate fixation. Oral Surg Oral Med Oral Pathol Oral Radiol Endod 2008; 106 : 656-61. 22) Dahlberg G: Statistical methods for medical and biological students. George Allen and Unwin, London, pp. 122-132. 1940. 
23) Hattori Y, Okugawa H, Watanabe M. Occlusal force measurement using dental prescale. J Jpn Prosthodont Soc 1994; 38: 835-41.

24) Proffit WA, Turvey TA, Fields HW, Phillips C. The effect of orthognathic surgery on occlusal force. J Oral Maxillofac Surg 1989; 47: 457-463.

25) Throckmorton GS, Buschang PH, Ellis E III. Improvement of maximum occlusal forces after orthognathic surgery. J Oral Maxillofac Surg 1996; 54: 1080-1086.

26) Throckmorton GS, Ellis E III, Sinn DP. Functional characteristics of retrognathic patients before and after mandibular advancement surgery. J Oral Maxillofac Surg 1995; 53: 898-908.

27) Schantz P, Randall-Fox E, Hutchinson W, Tyden A, Astrand PO: Muscle fiber type distribution, muscle cross-sectional area, and maximal voluntary strength in humans. Acta Physiol Scand 1983; 117: 219-226.

28) Ando T: Observation of the masticatory muscles and buccal fat pad on the CT images. J Natl Med Coll 1991; 16: 30-41.

29) Ueki K, Takazakura D, Marukawa K, Shimada M, Nakagawa K, Yamamoto E: Relationship between the morphologies of the masseter muscle and the ramus and the occlusal force in patients with mandibular prognathism. J Oral Maxillofac Surg 2006; 64: $1480-1486$.

30) Katsumata A, Nojiri M, Fujishita M, Ariji Y, Ariji E, Langlais RP: Condylar head remodeling following mandibular setback osteotomy for prognathism: A comparative study of different imaging modalities. Oral Surg Oral Med Oral Pathol Oral Radiol Endod 2006; $101: 505-14$.

31) Zhao Q, Hu J, Wang D, Zhu S: Change in the temporomandibular joint after mandibular setback surgery in monkeys: intraoral vertical versus sagittal split ramus osteotomy. Oral Surg Oral Med Oral Pathol Oral Radiol Endod 2007; 104 : 329-37. 
Figure Legends

Figure 1. Simulation of plate bending. The plates were bent to prevent the proximal segments from rotating internally. Note the gap between the osteotomy surfaces on both sides.

Figure 2. Measurements of masseter muscle and ramus. m1: Ramus length, m2: Ramus width, m3: Masseter length, m4: Masseter width, r1: Ramus area, r2: Masseter area.

Figure 3. Measurements of condyle. m1: Condylar length, m2: Condylar width, r1:condylar area.

Figure 4. Measurements of masseter vertical length and angle. Red line indicates masseter vertical length. The angle between the yellow arrows indicates masseter direction angle,

Figure 5. Results of a simple linear regression analysis. A) Preoperative occlusal force and condylar width, B) Preoperative occlusal force and masseter width, C) Preoperative occlusal contact and Masseter width.

Figure 6. Results of a simple linear regression analysis. A) Ramus area and masseter area preoperation, B) Ramus area and masseter area postoperation.

Table 1. Results of measurements with CT and occlusal force. Same small alphabet letters show significant difference at $\mathrm{P}<0.05$. 


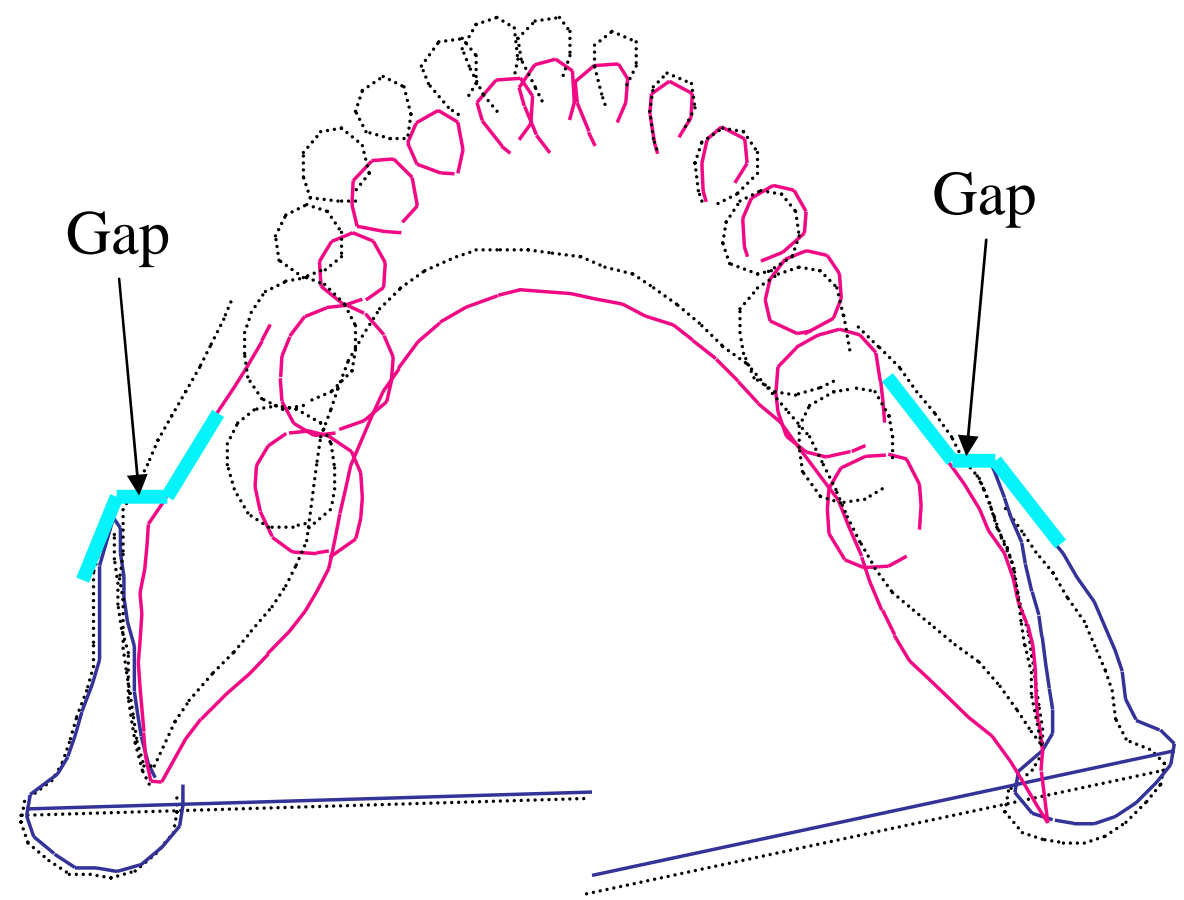

Fig.1 


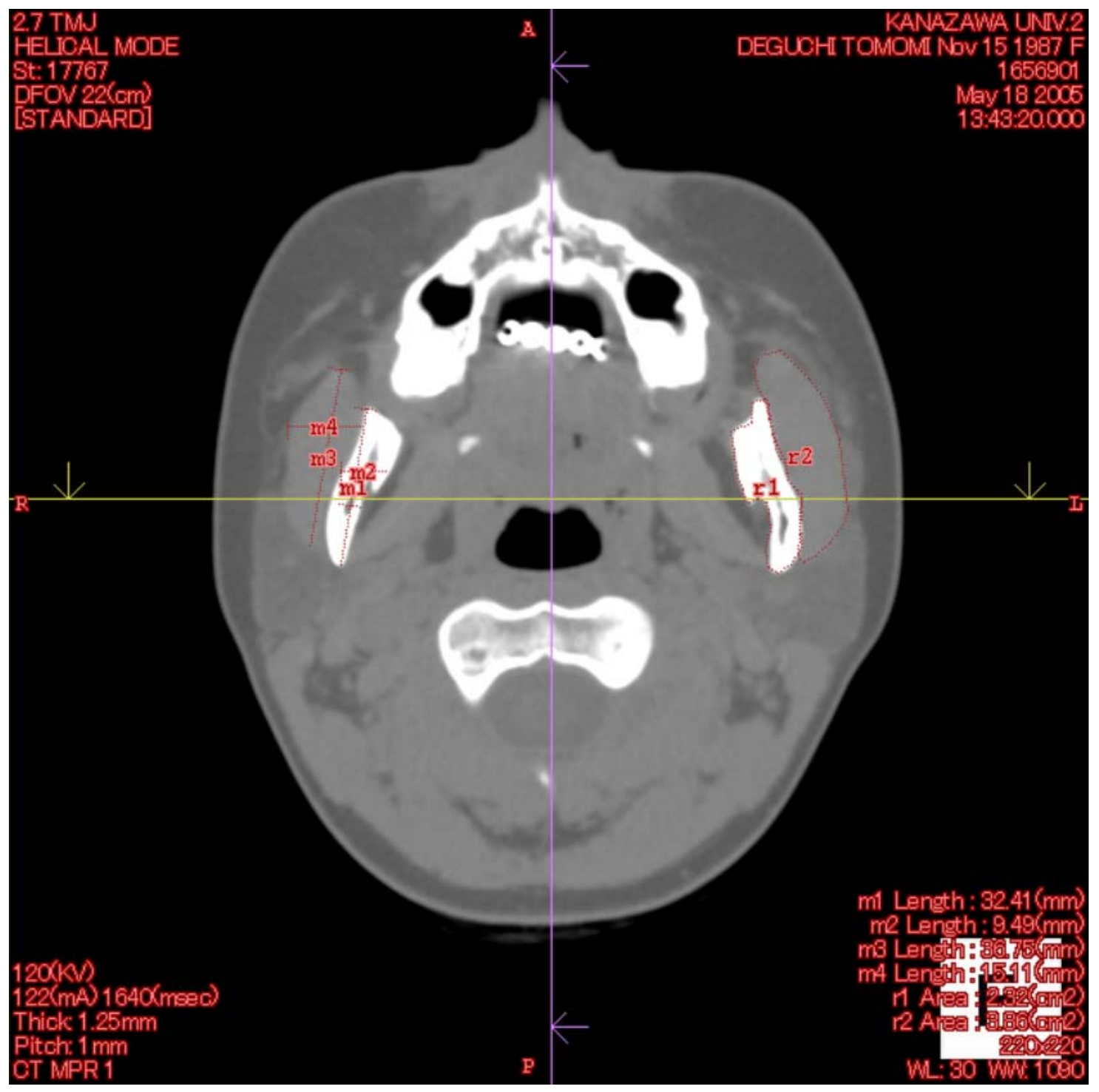

Fig.2 


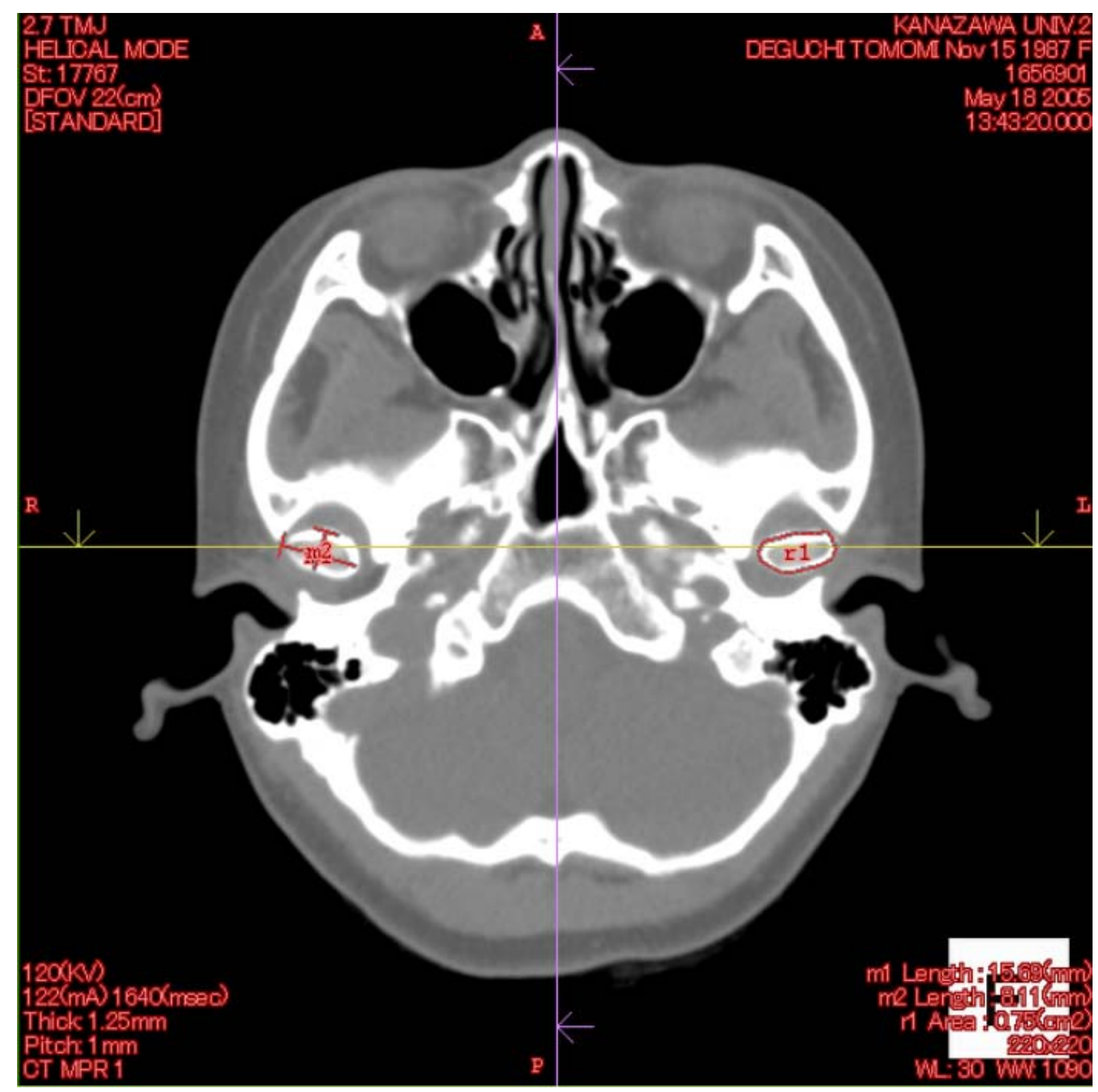

Fig.3 


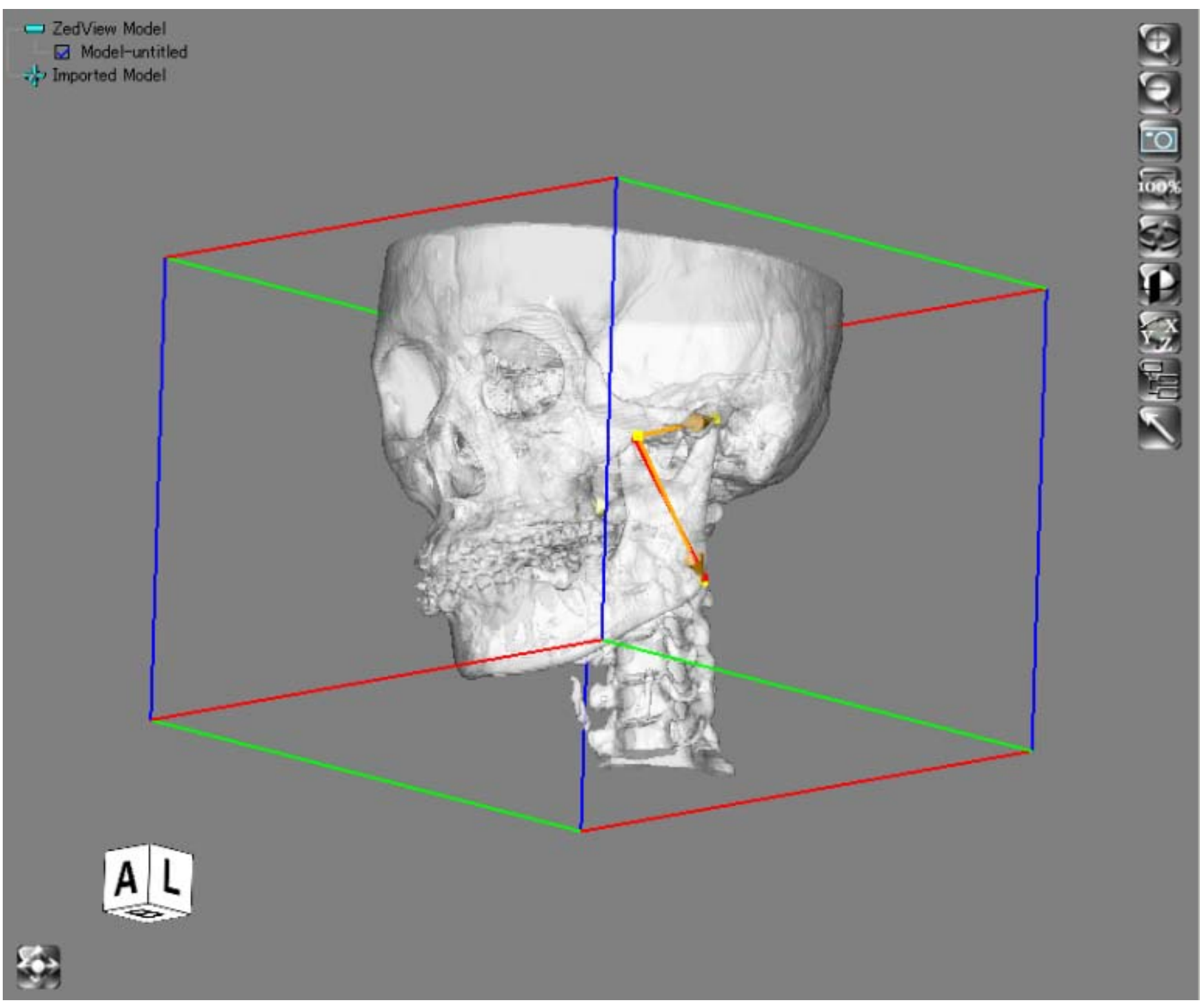

Fig.4 


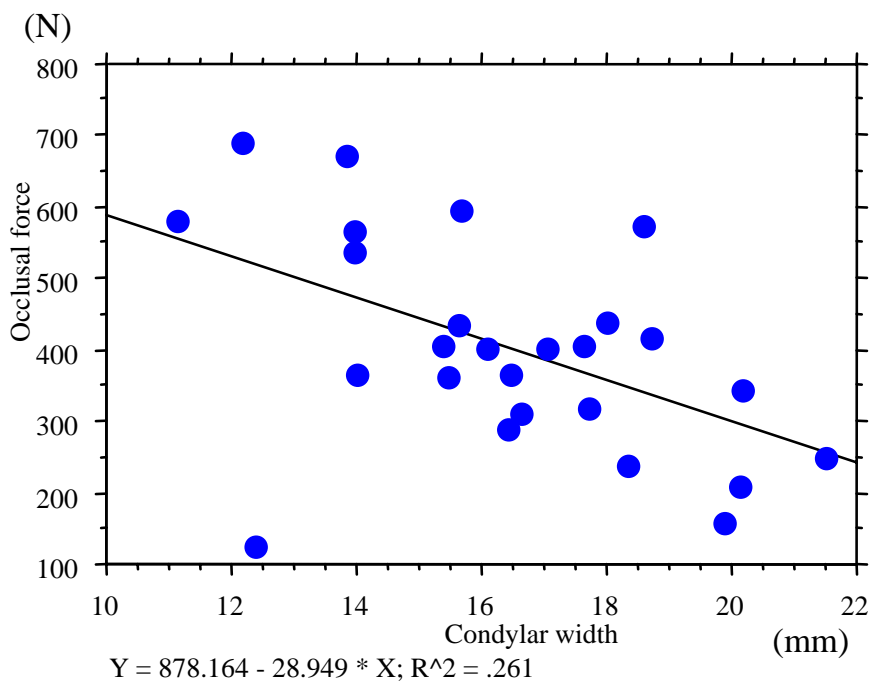

A

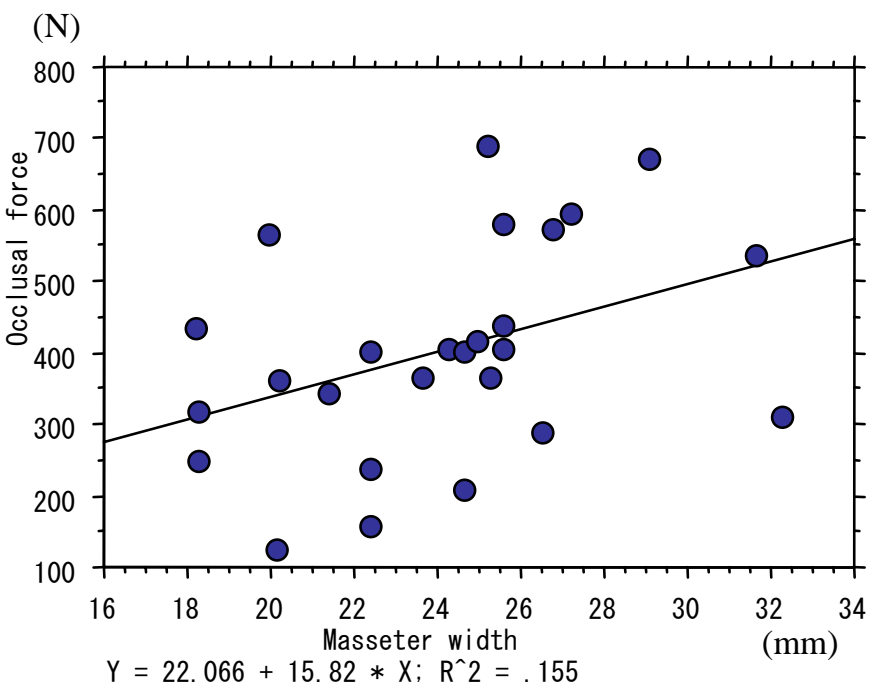

B

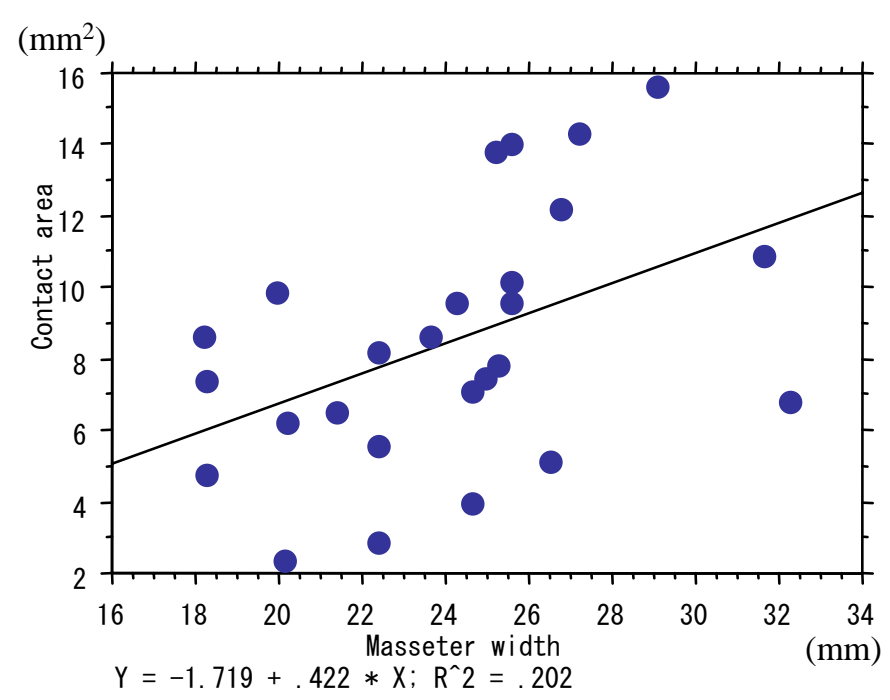

C

Fig.5 


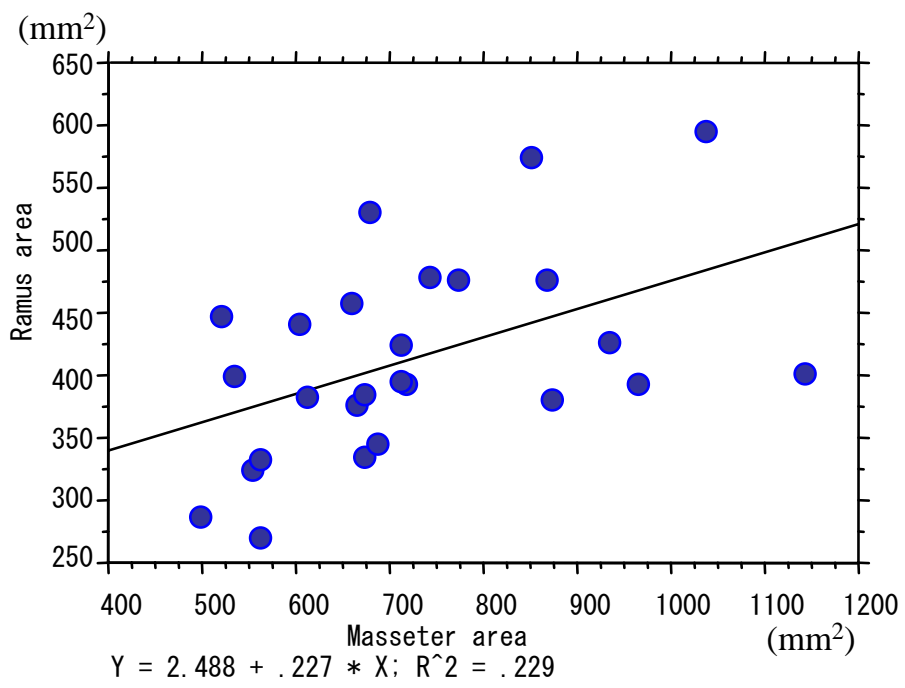

A

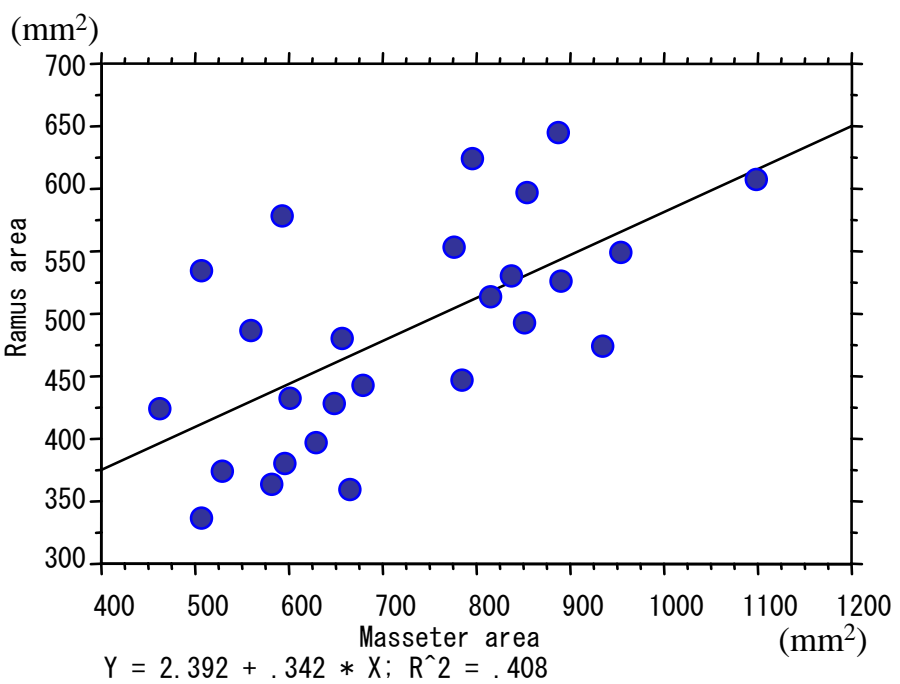

B

Fig.6 